\title{
Effect of Temperature on Grain Size in AA6063 Aluminum Alloy Subjected to Repetitive Corrugation and Straightening
}

\author{
N. Thangapandian ${ }^{1} \cdot$ S. Balasivanandha $\mathrm{Prabu}^{2} \cdot$ K. A. Padmanabhan ${ }^{2}$
}

Received: 28 August 2018 / Revised: 14 November 2018 / Published online: 1 January 2019

(c) The Chinese Society for Metals (CSM) and Springer-Verlag GmbH Germany, part of Springer Nature 2019

\begin{abstract}
The influence of processing temperature on grain size reduction in AA 6063 aluminum alloy subjected to repetitive corrugation and straightening (RCS) is investigated in this work. The aluminum alloy was processed by RCS at different temperatures (room temperature, $100{ }^{\circ} \mathrm{C}, 200{ }^{\circ} \mathrm{C}$ and $300^{\circ} \mathrm{C}$ ) till the maximum number of passes possible before failure and the mechanical properties such as tensile strength and hardness were measured. The grain size and their misorientation of grains of the processed samples were analyzed using the electron backscattered diffraction. The results indicated that the transformation of low-angle grain boundaries to high-angle grain boundaries and dislocation tangles were highly dependent on the strain imparted, which could be controlled by selecting the proper processing temperature. As a result, the mechanical properties are affected. In particular, the room temperature tensile strength and hardness values of the processed material decrease with increasing processing temperature.
\end{abstract}

Keywords Repetitive corrugation and straightening $\cdot$ Strain $\cdot$ Grain size reduction/refinement $\cdot$ EBSD $\cdot$ Strength $\cdot$ Hardness

\section{Introduction}

Bulk nanostructured materials/ultra-fine grained (BNM/ UFG) materials are presently thrust areas of research focus due to their potential engineering applications. They exhibit superior mechanical and superplastic properties compared with coarse grained materials. Of the many methods available to produce BNM/UFG materials, severe plastic deformation (SPD) is regarded as a viable route. Equal channel angular pressing (ECAP) [1], high-pressure torsion (HPT) [2], accumulative roll bonding (ARB) [3], twist extrusion [4] and repetitive corrugation and straightening (RCS) [5] are some of the prominent SPD techniques. Seventy percent of aluminum and its alloys are used in industry in the form of sheets and plates. ARB and RCS are the two processes which

Available online at http://link.springer.com/journal/40195

N. Thangapandian

erpandian@gmail.com

1 Department of Mechanical Engineering, St. Joseph's Institute of Technology, Chennai 600 119, India

2 Department of Mechanical Engineering, College of Engineering Guindy, Anna University, Chennai 600 025, India can be used to produce BNM/UFG materials in sheet/plate form. But, ARB is not commercially exploited as it often fails to acquire good bond strength between the sheets/plates in continuous passes.

Grain refinement and mechanical properties depend on the processing conditions and die configurations. The effect of die profile on grain refinement in RCS processing was reported earlier [5]. The microstructure and mechanical properties of commercially pure Ni sheets subjected to constrained groove pressing (CGP) using a flat groove die of three different groove lengths were reported by Wang et al. [6]. They concluded that the number of successful passes before failure increases with decreasing groove angle and a higher groove width led to poor grain refinement and inferior mechanical properties. In such a case, the stress imparted to the die was extremely low.

The microstructure and mechanical property of an aluminum alloy processed at different temperatures using the ECAP process has been studied extensively [7-9]. Mazurina et al. [7] studied the effect of processing temperature on aluminum alloy 2219 in the temperature range of $250-475{ }^{\circ} \mathrm{C}$. They concluded that the effect of pressing temperature on grain refinement was minimal in the average true strain range of $2<\varepsilon<4$. However, at $\varepsilon>4$, the processing temperature plays a significant role 
in determining the magnitude of dynamic recovery. The secondary precipitates can affect dislocation (re-)arrangements and stabilization of new grains significantly. In contrast, for aluminum alloy AA 7475 in the range of $250-400{ }^{\circ} \mathrm{C}$, starting with initial grain size $100-200 \mu \mathrm{m}$, Goloborodko et al. [8] obtained a crystallite/grain size of $0.6 \mu \mathrm{m}$ at $250{ }^{\circ} \mathrm{C}$ and $1.7 \mu \mathrm{m}$ at $400{ }^{\circ} \mathrm{C}$. When the strain exceeds 8 , the fraction of high-angle grain boundaries in the material reaches saturation, which leads to a conclusion that a lower temperature leads to the formation of new grains, ensuring a greater fraction of high-angle grain boundaries.

Grain refinement in pure titanium at $150{ }^{\circ} \mathrm{C}$ and $450{ }^{\circ} \mathrm{C}$ during ECAP was studied by Rodriguez-Calvillo and Cabrera [9]. At the end of 4 passes, a significant fraction of sub-grains with low-angle grain boundaries (LAGB) formed. The tensile strength was poor due to recovery in the specimens prepared at higher processing temperatures.

Although a few reports have examined the effect of die profile on mechanical properties $[5,10]$, to the best of our knowledge, no attempts have so far been made to study the effect of temperature on RCS processing though this aspect has been studied in ECAP and twist extrusion. RCS is a highly inhomogeneous deformation process. An increase in the processing temperature favors more homogeneous strain distribution, but a higher processing temperature does not favor the maximization of grain refinement. The objectives of this work are to make an attempt to fill the existing gap in knowledge and also examine grain size evolution within the selected temperature range. This work also focuses on structure, property and correlation as a function of the number of passes at different temperatures. SPD processing depends on deforming the material below the recrystallization temperature to avoid material softening. Therefore, the temperature range used was kept below the recrystallization temperature [such as room temperature (RT), $100{ }^{\circ} \mathrm{C}, 200{ }^{\circ} \mathrm{C}$ and $300{ }^{\circ} \mathrm{C}$ ]. The uniformity of imparted strain as a function of temperature was analyzed by hardness measurements.

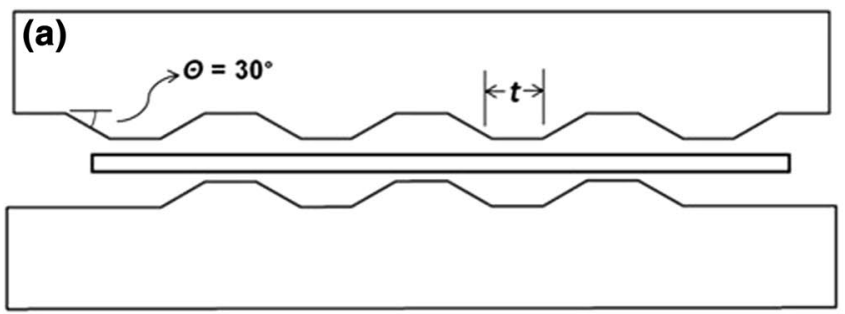

\section{Experimental}

AA6063-0 aluminum alloy sheets of $3 \mathrm{~mm}$ thickness were subjected to the RCS process at four temperatures (RT, $100{ }^{\circ} \mathrm{C}, 200^{\circ} \mathrm{C}$ and $300{ }^{\circ} \mathrm{C}$ ). The composition of the alloy, determined as per ASTM E-1251-11, was as follows (wt\%): $\mathrm{Al}$ 97.5, Mg 0.84, Si 0.776, Fe 0.45, Cu 0.183, Ti 0.021, Cr $0.202, \mathrm{~V} 0.008$. The effect of temperature was studied using a flat grooved corrugation die. One set of flat die was used for straightening. The dimensions of the flat grooved die are shown in Fig. 1 (length $t=5 \mathrm{~mm}$, angle $\theta=30^{\circ}$ ). One corrugation and straightening is considered as a single pass. The specimens were rotated $180^{\circ}$ after every pass to achieve uniform grain refinement.

The corrugated die and specimens were heated inside a muffle furnace mounted on a hydraulic press at a heating rate of $5{ }^{\circ} \mathrm{C} / \mathrm{min}$. Temperature was maintained using a thermocouple. All the sides of the furnace were closed, but during pressing the top door was opened and to compensate the loss in heat the temperature of the furnace was kept slightly higher (optimized by trial and error).

Samples were processed at each temperature to the maximum number of passes possible before fracture. Formation of cracks restricts the number of passes to 8 at RT and $100{ }^{\circ} \mathrm{C}$, but at the other two processing temperatures there were no surface cracks even after 10 passes. For comparison, the samples processed up to 8 passes were chosen (common maximum number of passes possible at all the temperatures employed). Samples were cut as per ASTM E8-M standard for tensile testing (on Instron machine 3369, USA). The micro-hardness tests were carried out on each sample at 5 different locations along the length of the specimen. Load applied was $500 \mathrm{~g}$, and the dwell time was $10 \mathrm{~s}$. The microstructure characteristics were identified using electron back scattered diffraction (EBSD, FEI QUANTA, USA). Extreme care was taken during EBSD measurements to eliminate residual stresses while preparing the specimens (polished with emery sheets, followed by colloidal silica wet polish). XRD measurements were also taken on the parent alloy, and the samples were subjected to 8 passes at different temperatures.

(b)

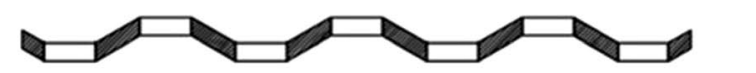

Fig. 1 Schematic of a corrugation die, b straightening die 


\section{Results and Discussion}

\subsection{Hardness}

Hardness measurements were taken at a regular interval of $10 \mathrm{~mm}$ along the length of the specimen. The average room temperature hardness and its variation with respect to the number of the passes at different processing conditions are presented in Fig. 2.

In the specimens processed at RT and $100{ }^{\circ} \mathrm{C}$, hardness continued to increase due to work hardening till the maximum number of passes. Evidently, at this temperature work hardening prevailed over recovery/recrystallisation. The room temperature hardness almost doubled at the end of the 8th pass. But processing at a higher temperature tends to annihilate the dislocations and soften the material. Therefore, during processing at $200{ }^{\circ} \mathrm{C}$ and $300{ }^{\circ} \mathrm{C}$, in the first two passes, recovery dominated over work hardening, but with more strain the converse became true in the range of 2-6 passes, when the maximum in hardness was reached (i.e., recovery could not keep pace with work hardening). In the range of hardness decrease, dislocation annihilation rate and hence the hardness drop were higher at an elevated temperature due to the large strain and temperature effects, which allow sufficient time/thermal activation for dislocation rearrangement [11]. In contrast, after processing at $100{ }^{\circ} \mathrm{C}$, there was no initial hardness drop due to grain refinement, a consequence of limited recovery, which could not fully offset the effects of work hardening (see later for experimental evidence). At $200{ }^{\circ} \mathrm{C}$ and $300{ }^{\circ} \mathrm{C}$, after 8 passes, the combined effect of accumulated strain and temperature caused significant dynamic recovery and reduced the hardness value. Grain rotation and grain coalescence also occur more easily at higher temperatures

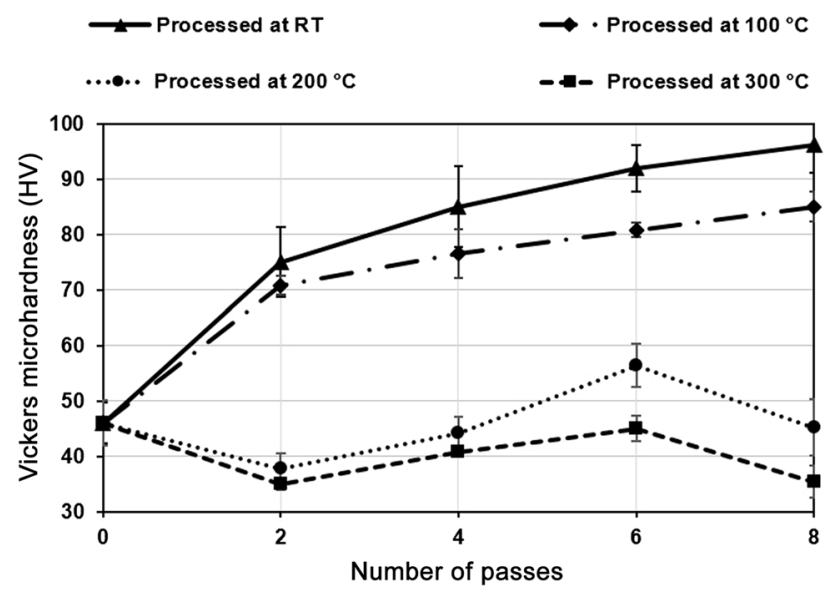

Fig. 2 Room temperature hardness for AA6063 alloy processed at RT and three elevated temperatures and higher strains [12], which could also contribute to the above observations.

\subsection{Tensile Strength}

The engineering stress-strain curves for the alloy processed at four different temperatures are shown in Fig. 3. The parent material has an ultimate tensile strength of $110 \mathrm{MPa}$, while the alloy processed at RT displays a maximum strength of $189 \mathrm{MPa}$ at the end of the 4th pass. Further processing results in strength reduction. As explained earlier, during the initial passes, work hardening is dominant. In the later passes, significant dynamic recovery and development of the surface flaws cause a reduction in strength. At $100{ }^{\circ} \mathrm{C}$, the strength improvement is slightly lower than that during the RT processing. The maximal strength achieved in the material processed at $100{ }^{\circ} \mathrm{C}$ is $164 \mathrm{MPa}$.

As already pointed out, at the higher temperatures of $200{ }^{\circ} \mathrm{C}$ and $300^{\circ} \mathrm{C}$, recovery processes dominate over strain hardening and so the number of passes without surface cracking could go to up to 10 . But grain refinement is less than what is usually seen after ECAP [8]. The more constrained flow in ECAP leads to the development of residual and thermal stresses in addition to greater grain refinement.

At $200{ }^{\circ} \mathrm{C}$ and $300{ }^{\circ} \mathrm{C}$, the maximum in the ultimate tensile strength (UTS) is seen at the end of the 4th pass. After that the decrease in strength was mainly due to softening, caused by increased exposure time at an elevated temperature. In contrast, at $100{ }^{\circ} \mathrm{C}$, this maximum is present after the 6th pass. After the 8th pass, the strength is reduced perhaps due to the internal cracks.

At the end of 8 passes, the tensile strength of the specimens processed at $100{ }^{\circ} \mathrm{C}, 200{ }^{\circ} \mathrm{C}$ and $300{ }^{\circ} \mathrm{C}$ is $164 \mathrm{MPa}$, $152 \mathrm{MPa}$ and $138 \mathrm{MPa}$, respectively. Dynamic recovery (DRV) and recrystallization play an important role during the later passes. However, the presence of magnesium reduces the rate of recovery and the formation of stable grains [13]. Also, high-temperature processing facilitates dynamic precipitation [14]. As is usually the case, material softening is accompanied by an increase in ductility. Room temperature strain at fracture increases from 0.26 to 0.36 on increasing the processing temperature from 100 to $300{ }^{\circ} \mathrm{C}$. This improved ductility is attributed to the fully recrystallized microstructure that has resulted from the processing in the latter case.

\subsection{Activation Energy}

RCS processing at elevated temperatures, as done in the present experiments, is under dynamic conditions involving severe strain. Therefore, to identify the likely operating mechanisms in the temperature interval of $100-300{ }^{\circ} \mathrm{C}$, tensile tests were carried out on an Instron machine, as mentioned earlier. 

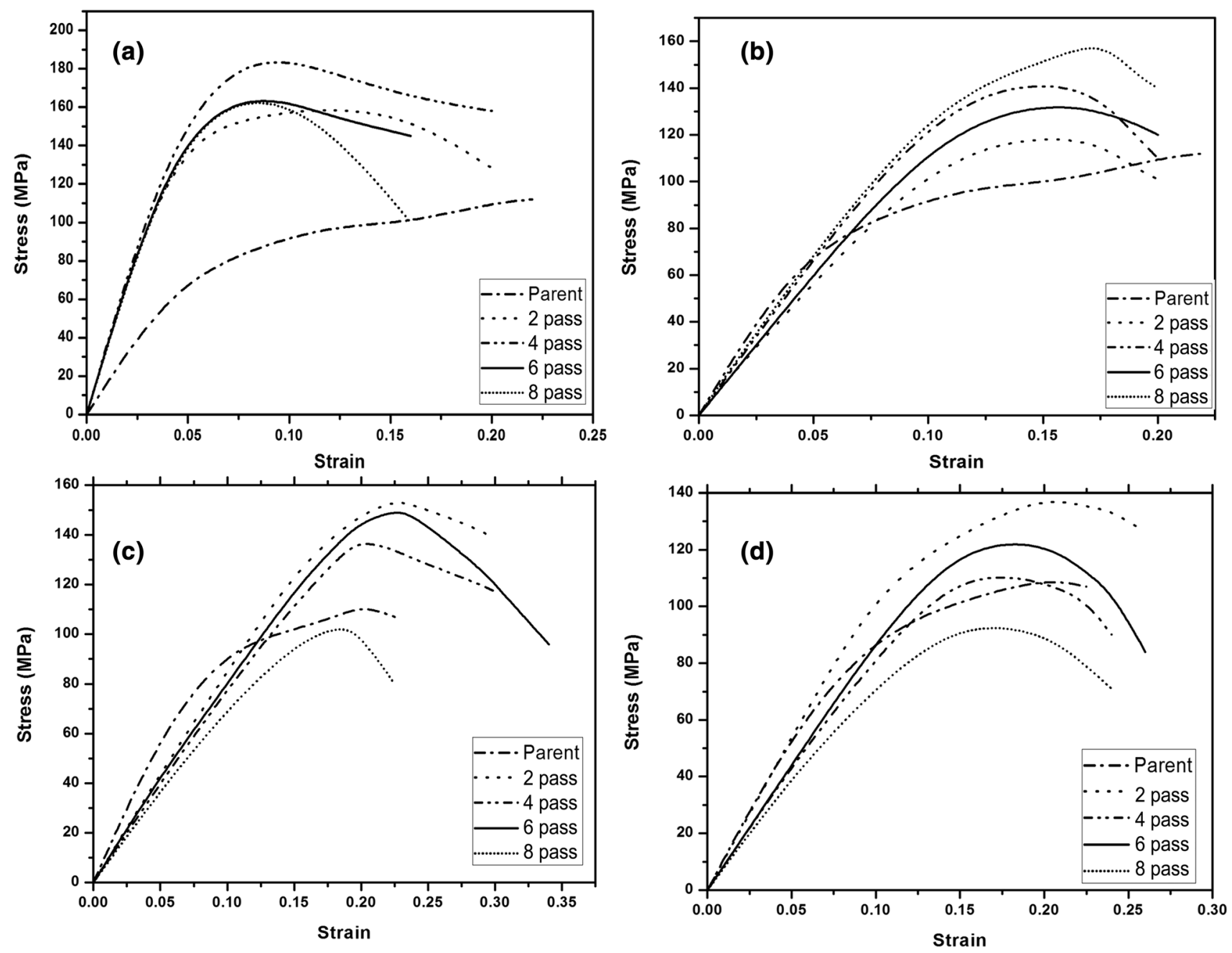

Fig. 3 Stress-strain curves for alloy AA6063: a processed at RT, b processed at $100{ }^{\circ} \mathrm{C}$, c processed at $200{ }^{\circ} \mathrm{C}$, $\mathbf{d}$ processed at $300{ }^{\circ} \mathrm{C}$

A constant crosshead velocity of $0.04 \mathrm{~mm} / \mathrm{s}$ was employed at each of the three temperatures $\left(100^{\circ} \mathrm{C}, 200^{\circ} \mathrm{C}, 300^{\circ} \mathrm{C}\right)$. From the resultant stress-strain curves, the nominal strain rates at the three temperatures corresponding to a constant stress of $80 \mathrm{MPa}$ (with increasing temperature, the strain rate at a given stress increases) were calculated. Low-stress, high-temperature deformation is often represented by the power law equation:

$\dot{\varepsilon}=A \sigma^{n} \exp \left(\frac{-Q}{R T}\right)$,

where $\dot{\varepsilon}$ is the strain rate; $\sigma$ is the stress, which is kept constant in this case; $Q$ is the activation energy for the rate controlling process; $n$ is the stress exponent; $A$ is a constant; $R$ is the gas constant and $T$ is the absolute temperature of deformation. In general, $n$ is a function of both temperature and stress. But, in narrow temperature and strain rate intervals, it is often taken to be a constant. Then, in the $\ln \dot{\varepsilon}$ versus $(1 / T)$ plot the slope will be equal to $(-Q / R)$. Thus, it

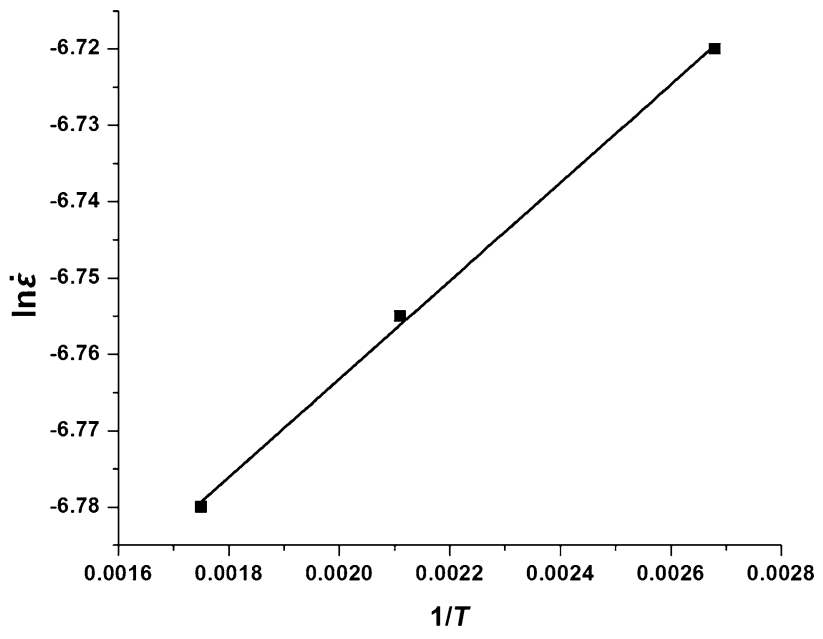

Fig. 4 Arrhenius plot to determine activation energy for rate controlling process 
is easy to arrive at the activation energy for the rate controlling process, as shown in Fig. 4.

Following the above procedure, an activation energy of $\sim 256 \mathrm{~kJ} / \mathrm{mol}$ was obtained in the present study using the method of least squares. This value is slightly greater than the value reported for the same alloy $(232.35 \mathrm{~kJ} / \mathrm{mol}$; rather close considering the exponential dependence of temperature and given the accuracy possible in diffusion measurements) [15]. This small difference is attributed to the differences in the microstructure and the chemical composition, which is in consistent with the previous studies $[16,17]$. Although speculations are indulged in by comparing the activation energy obtained by the authors with the values reported concerning bulk and grain boundary diffusion, here we shall refrain from doing so because of these factors: (a) reliable diffusion data are not available for complex industrial alloys; (b) more than one physical mechanism can have very close activation energy values; (c) detailed microstructural and topological evidence is necessary for unequivocal inference concerning operating mechanisms at the level of the atomistics.

Mazurina et al. [7] reported that an increase in temperature barely affects the mechanical properties and microstructures in case of ECAP processing. In contrast, after RCS processing, as carried out here, the temperature of processing is found to affect both the microstructure and the mechanical properties drastically. This is because of the significant effect of temperature on recovery, recrystallization and precipitation in the temperature range employed [18].

\subsection{Microstructures}

Figure 5a and $\mathrm{b}$ shows the grain boundary (GB) mapping and grain size distribution of unprocessed AA6063 aluminum alloy. The average grain size is $\sim 40 \mu \mathrm{m}$. Figure $5 \mathrm{c}$ displays the fraction of high-angle grain boundaries (HAGBs) and taken together with Fig. 4a. It is clear that the parent material has equiaxed grains with a large fraction of HAGBs.

Figure 6 presents the grain boundary characteristic and size distribution map of AA6063 alloy processed at three temperatures. It is clear that an increase in the processing temperature increases the post-processing grain size. Grain refinement is more when the alloy is processed at $100{ }^{\circ} \mathrm{C}$ than at RT. At the end of 4, 6 and 8 passes (processed at $100{ }^{\circ} \mathrm{C}$ ), the grain sizes were 7,8 and $7 \mu \mathrm{m}$, respectively (Fig. 6d, e). Colonies of new grains are formed inside bigger grains throughout the specimen. When the imparted strain reaches an intermediate level (above $\sim 2$ ), new dislocation structures form. The reduction in grain size observed after the 4th and the 6th passes is a result of these dislocation structures turning into sub-grains with low-angle boundaries, then high-angle grain boundaries and finally new recrystallized grains. But the grain refinement as a result of $\mathrm{RT}$ processing is not significant compared with what is seen after the $100^{\circ} \mathrm{C}$ processing.

Figure $6 \mathrm{f}-1$ displays the data for the considerable grain growth present due to an increase in the processing temperature. This is because at the elevated temperatures, particularly above $200^{\circ} \mathrm{C}$, dynamic recovery and recrystallization are significant. Once recrystallization has set in, with increasing time, grain growth is quite perceptible. After 8 passes, at $200{ }^{\circ} \mathrm{C}$ and $300{ }^{\circ} \mathrm{C}$ the average grain size is around $150 \mu \mathrm{m}$ (Fig. 6i) and $250 \mu \mathrm{m}$ (Fig. 6l), respectively. In the orientation map (Fig. 6g-1), the secondary particles/ precipitates (black dots) are also visible (evidence for straininduced precipitation). The increase in temperature ensured uniform distribution of precipitates as well as effective solution. The presence of the precipitates retards the rate of recovery and ensures the retention of fine grains [7].

The grain size distribution map is presented in Fig. 7. Room temperature processing yields a grain size of around $20 \mu \mathrm{m}$ at the end of the 6th pass. After that the grain size increases enormously in the micrographed region, which
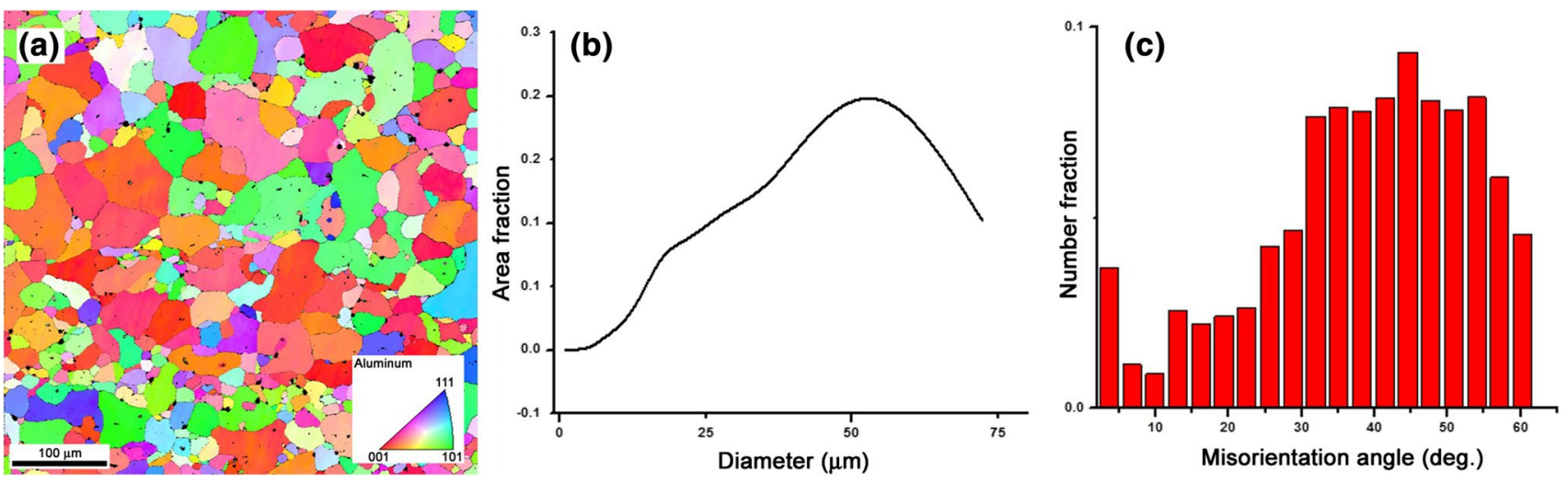

Fig. 5 a EBSD GB map, b grain size distribution, c misorientation angle map of AA6063 alloy 


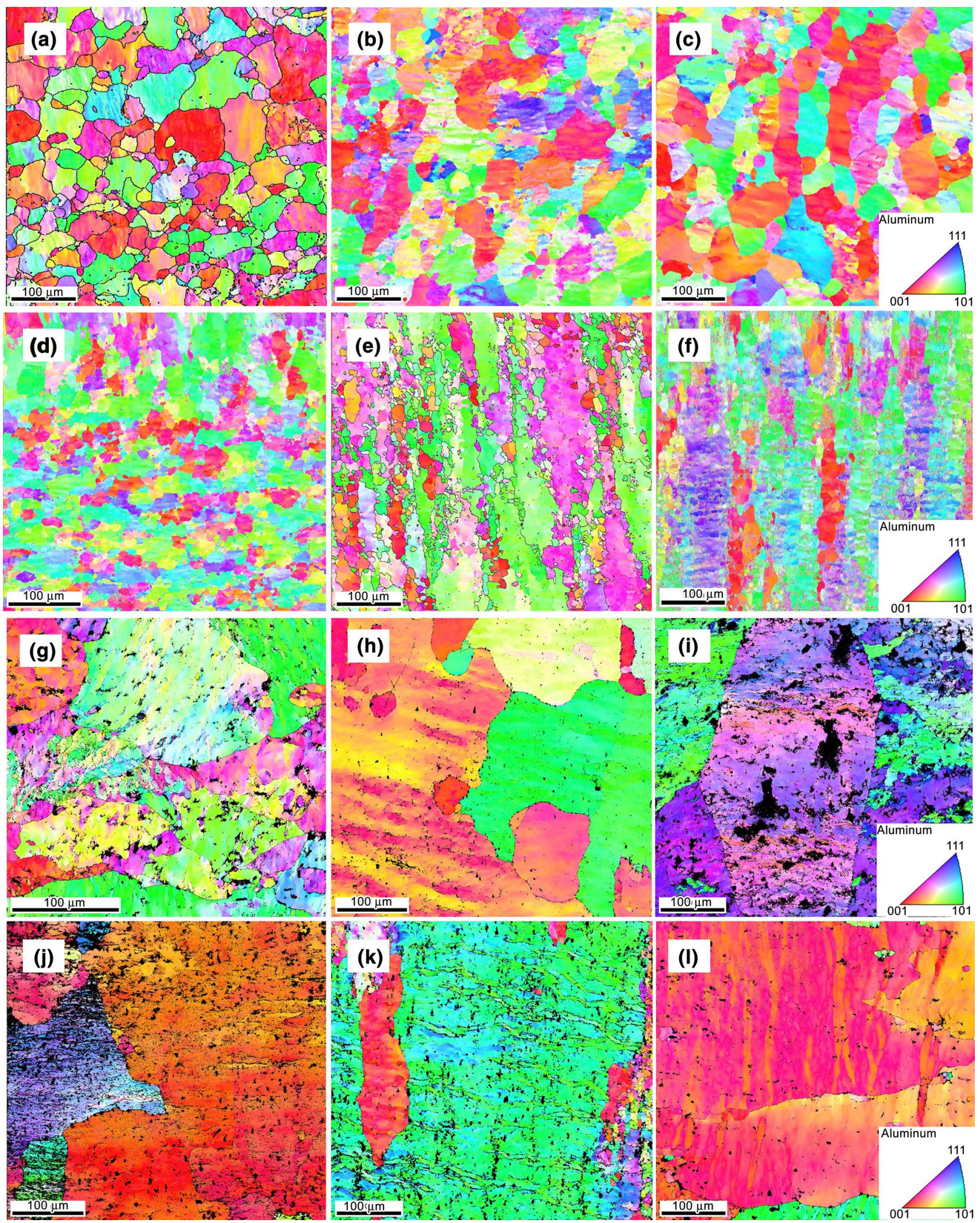

Fig. 6 EBSD images of AA6063 after a 4 passes at RT, b 6 passes at RT, c 8 passes at RT, $\mathbf{d} 4$ passes at $100{ }^{\circ} \mathrm{C}$, e 6 passes at $100{ }^{\circ} \mathrm{C}, \mathbf{f} 8$ passes at $100{ }^{\circ} \mathrm{C}, \mathbf{g} 4$ passes at $200{ }^{\circ} \mathrm{C}, \mathbf{h} 6$ passes at $200{ }^{\circ} \mathrm{C}, \mathbf{i} 8$ passes at $200{ }^{\circ} \mathrm{C}, \mathbf{j} 4$ passes at $300{ }^{\circ} \mathrm{C}, \mathbf{k} 6$ passes at $300{ }^{\circ} \mathrm{C}, 18$ passes at $300{ }^{\circ} \mathrm{C}$ 

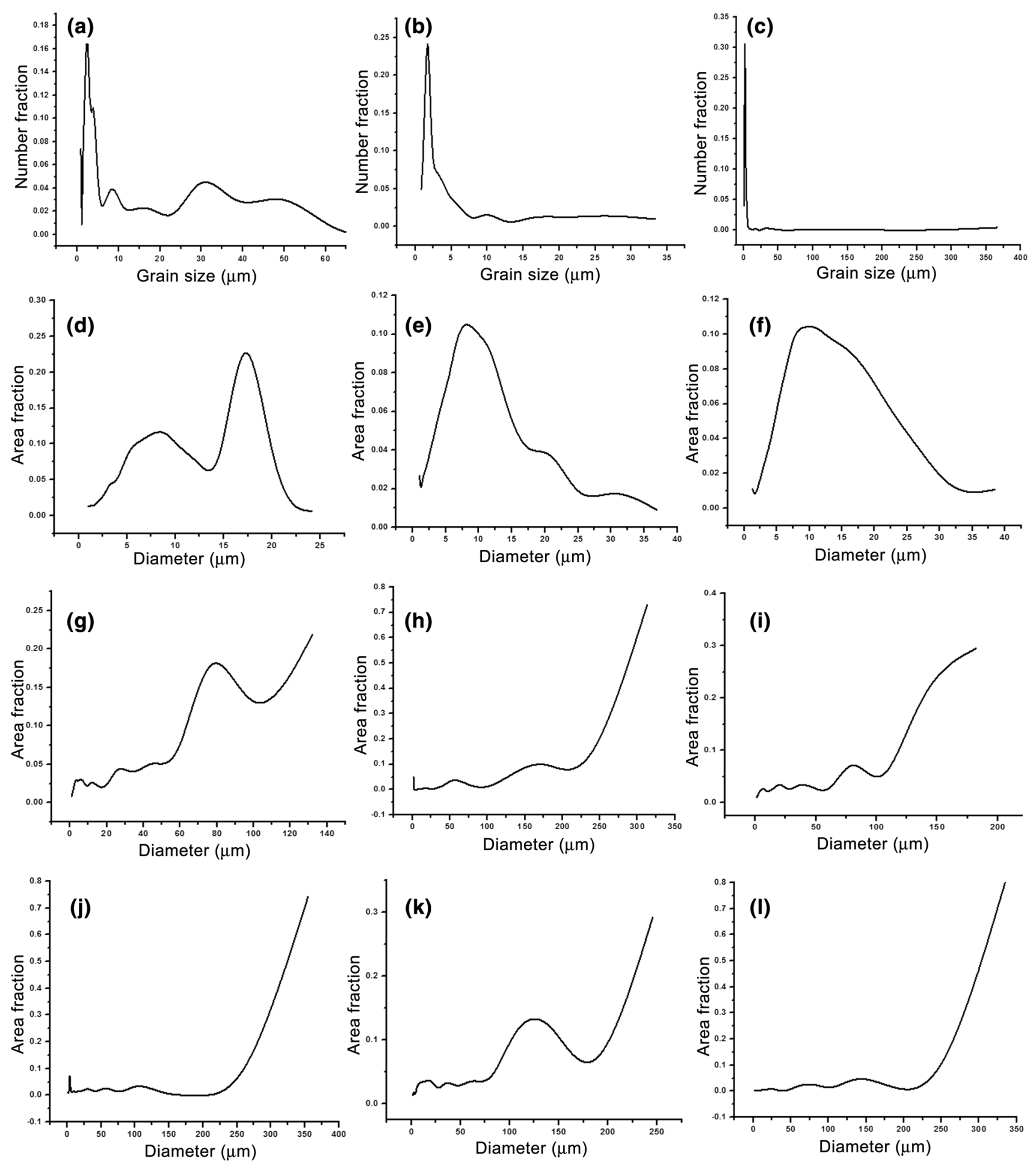

Fig. 7 Grain size distribution in AA6063 after a 4 passes at RT, b 6 passes at RT, c 8 passes at RT, d 4 passes at $100{ }^{\circ} \mathrm{C}$, e 6 passes at $100{ }^{\circ} \mathrm{C}$, f 8 passes at $100{ }^{\circ} \mathrm{C}, \mathbf{g} 4$ passes at $200{ }^{\circ} \mathrm{C}, \mathbf{h} 6$ passes at $200{ }^{\circ} \mathrm{C}, \mathbf{i} 8$ passes at $200{ }^{\circ} \mathrm{C}, \mathbf{j} 4$ passes at $300{ }^{\circ} \mathrm{C}, \mathbf{k} 6$ passes at $300{ }^{\circ} \mathrm{C}, \mathbf{1} 8$ passes at $300{ }^{\circ} \mathrm{C}$

may be due to sampling error. Following processing at $100{ }^{\circ} \mathrm{C}$, the average grain size is $\sim 7 \mu \mathrm{m}$. A few big grains were also seen in the processed specimen. At the higher temperatures $\left(200{ }^{\circ} \mathrm{C}\right.$ and $\left.300{ }^{\circ} \mathrm{C}\right)$, the peak shifts toward the right (Fig. $7 \mathrm{~g}-1$ ), i.e., grain growth is present. After the initial pass, in all cases a small peak at about $1 \mu \mathrm{m}$ and the 
presence of dislocation cells/sub-grains could be confirmed. After more number of passes, evidence for the rotation of dislocation cells/sub-grains and their coalescence into a few big grains could be found [19]. At higher temperatures, grain coalescence, in fact, takes place very easily, see, for example, Figs. $6 \mathrm{~g}-1$ and $7 \mathrm{~g}-1$.

Figure 8 presents the misorientation angle fraction in the alloy processed under different conditions. Compared
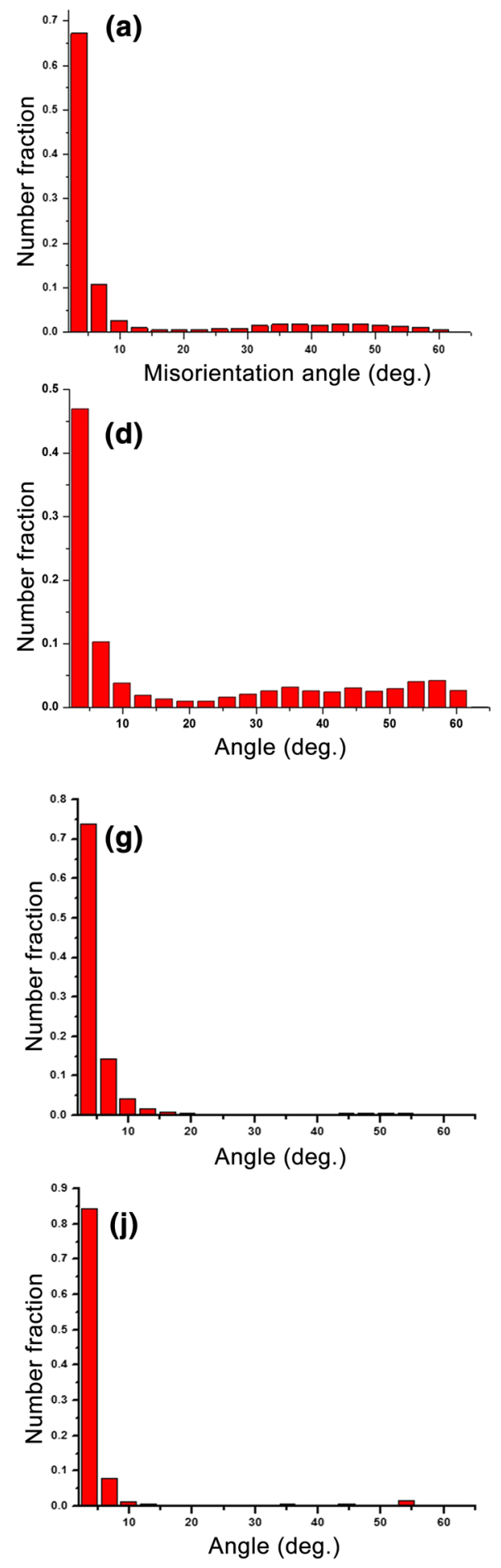
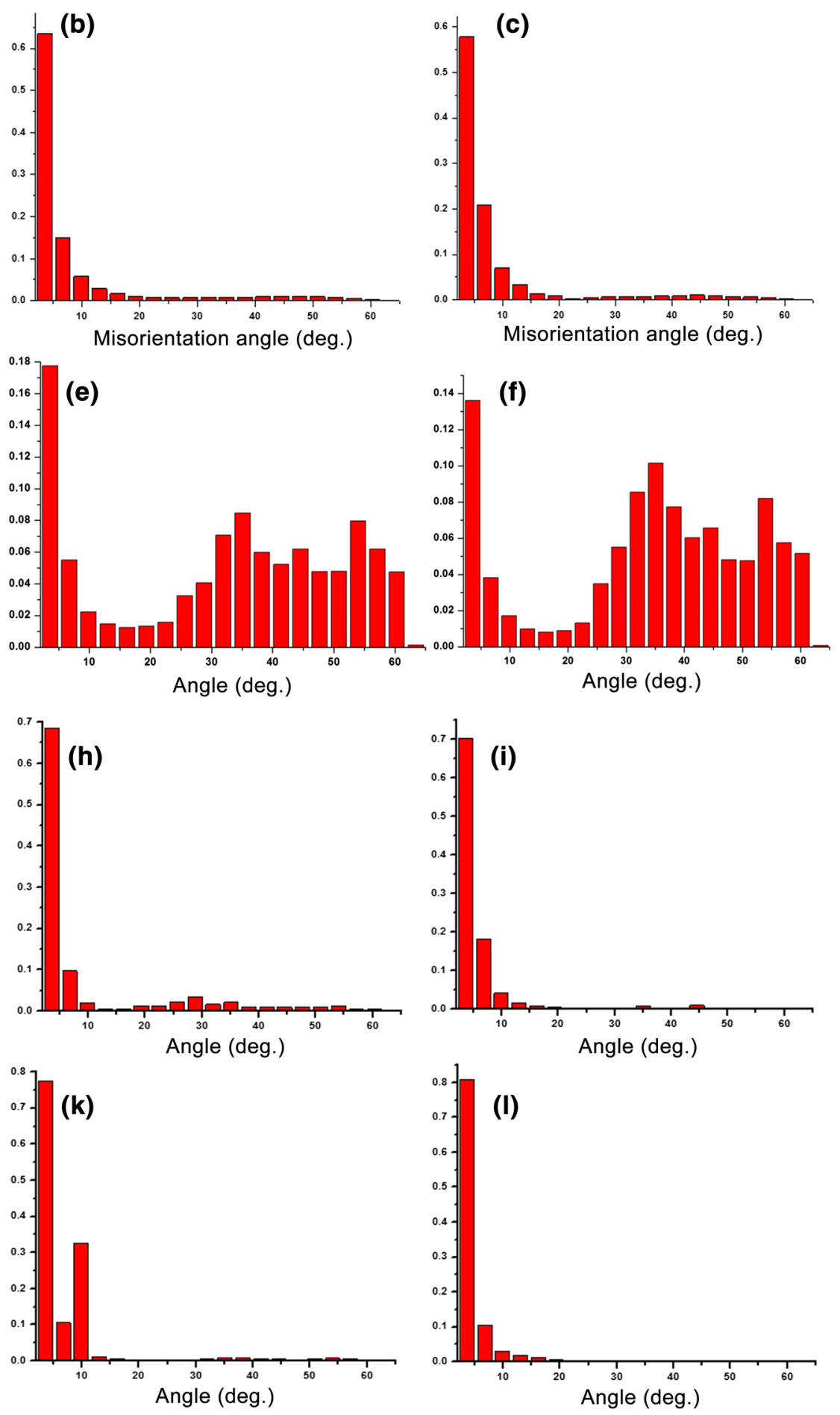

Fig. 8 Misorientation angle fraction in AA6063 after different treatments: a 4 passes at RT, b 6 passes at RT, c 8 passes at RT, d 4 passes at $100{ }^{\circ} \mathrm{C}$, e 6 passes at $100{ }^{\circ} \mathrm{C}, \mathbf{f} 8$ passes at $100{ }^{\circ} \mathrm{C}, \mathbf{g} 4$ passes at $200{ }^{\circ} \mathrm{C}, \mathbf{h} 6$ passes at $200{ }^{\circ} \mathrm{C}, \mathbf{i} 8$ passes at $200{ }^{\circ} \mathrm{C}, \mathbf{j} 4$ passes at $300{ }^{\circ} \mathrm{C}, \mathbf{k} 6$ passes at $300{ }^{\circ} \mathrm{C}, 18$ passes at $300{ }^{\circ} \mathrm{C}$ 
with the parent material, the HAGB fraction is less in all the processed samples. Figure $8 \mathrm{a}-\mathrm{c}$ reveals the HAGB fraction present in the specimen processed at RT. Figure $8 \mathrm{~d}-\mathrm{f}$ shows the HAGB fraction of the alloy processed at $100{ }^{\circ} \mathrm{C}$, which has the highest HAGB fraction compared with the other three conditions. This is because the formation of new grains is assisted by the (small) temperature increase. But increasing the temperature beyond the critical limit will cause the annihilation of dislocations and GBs. Evidently, the HAGB fraction increases with increasing number of passes in all cases, which is consistent with the earlier work of An et al. [20]. In addition, after the 6th pass, in all three conditions the HAGB fraction was very significant, i.e., new fine grains formed as a result of the strain imparted in that pass. The presence of such fine grains is the main reason for the improvement in the strength and hardness of the alloy.

Figure $8 \mathrm{~d}-\mathrm{i}$, corresponding to processing at $200{ }^{\circ} \mathrm{C}$ and $300{ }^{\circ} \mathrm{C}$, reveals that the HAGB fraction is lower in these cases compared with the samples processed at $100{ }^{\circ} \mathrm{C}$. This is due to that the grain size is larger at higher temperatures (less grain boundary and high-angle grain boundary areas) $[8,21]$. Though a uniform microstructure is achieved through increasing the temperature, other factors such as rate of recovery and formation of deformation twins and stacking faults also play a significant role in uniform grin refinement [22].
Electron backscattered images were indexed, and the inverse pole figure images were obtained using a commercial software package, as shown in Fig. 9. These pole figure images are used to identify the nature of the deformed samples and their grain orientation. Near-equiaxed, small grains in the sample processed at Fig. 9a-c imply a weak, nonexistent grain orientation. In contrast, in Fig. 9d-f, strong texture indicates that the deformed grains are highly oriented parallel to the rolling direction and possess stronger grain boundaries, which resist deformation to a greater extent compared with a sample processed at room temperature.

\subsection{Residual Stress Measurements}

Figure 10 shows the diffraction patterns for the various RCS processed specimens. The presence of $\mathrm{Mg}_{2} \mathrm{Si}, \mathrm{CuAl}_{2}$ and $\mathrm{AlFeSi}$ is confirmed from the XRD patterns. These precipitates are found in the parent and the processed samples. A small intensity peak for these precipitates can be correlated to the low concentrations of these phases. The XRD patterns of the alloy processed at high temperatures are slightly shifted toward left compared with the alloy processed at RT. This is mainly due to the uniformly imparted strain at the elevated temperatures. It is found that the decrease of $2 \theta$ by applying high plastic strain increases the lattice parameter. In addition, this result proves that residual stress is present. The residual compressive stress of the processed sample is
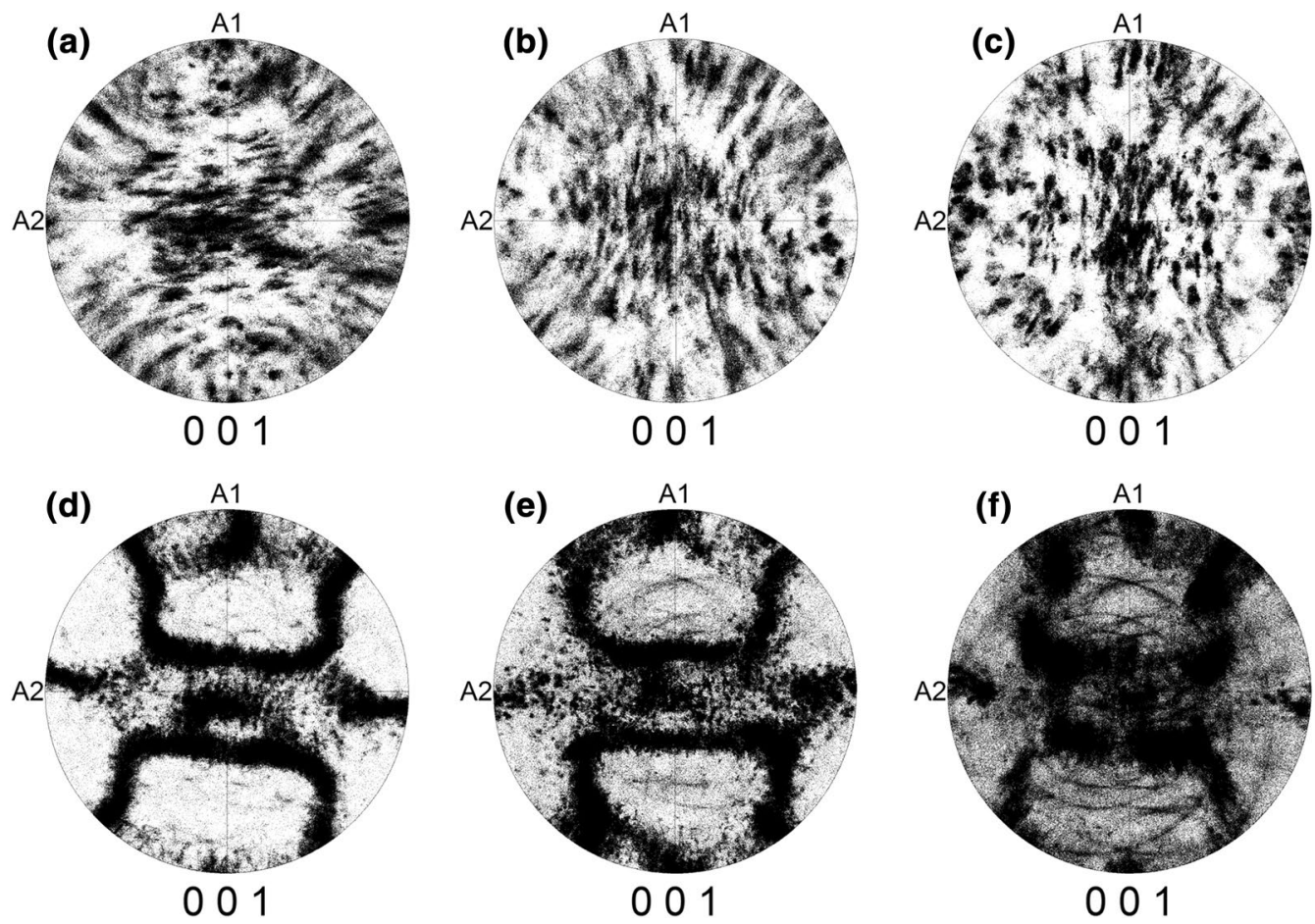

Fig. 9 Inverse pole figures of alloy after RCS at different temperatures: a 4 passes at RT, b 6 passes at RT, c 8 passes at RT, d 4 passes at $100{ }^{\circ} \mathrm{C}$, e 6 passes at $100{ }^{\circ} \mathrm{C}, \mathbf{f} 8$ passes at $100{ }^{\circ} \mathrm{C}$ 


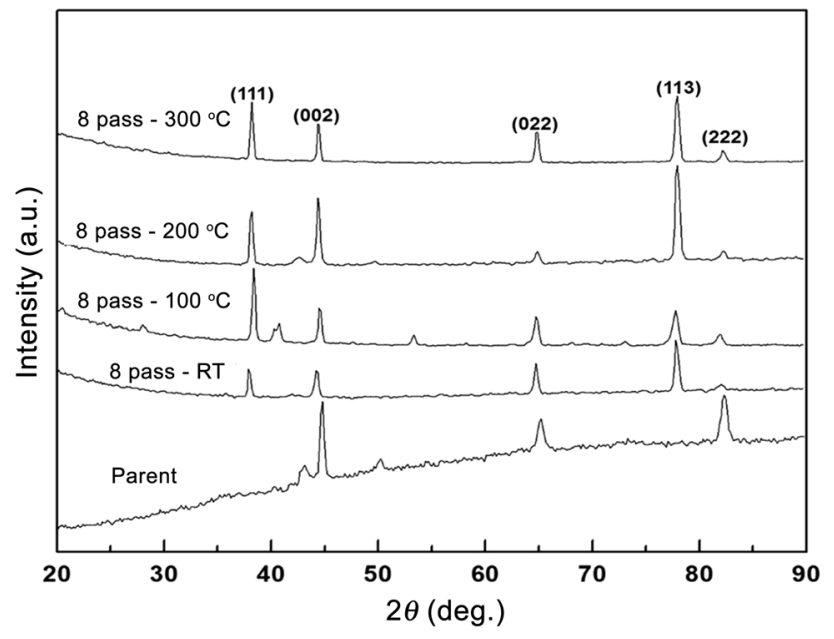

Fig. $10 \mathrm{XRD}$ patterns of alloy after RCS at different temperatures

calculated and compared with the parent material. All the processed samples exhibit a residual compressive value in the range of $\sim 25 \mathrm{MPa}$, which is slightly higher than what is found in the parent material.

\section{Conclusions}

The mechanical properties and microstructural characteristics of AA6063 alloy processed at different temperatures using RCS were studied, and the following conclusions could be drawn:

1. The microstructures show that a small increase in temperature can cause effective grain refinement in SPD processing. The smallest grain sizes were achieved in the alloy processed at $100{ }^{\circ} \mathrm{C}$.

2. The mechanical properties and microstructural characteristics obtained at the lower temperatures $\left(\mathrm{RT}, 100{ }^{\circ} \mathrm{C}\right.$ ) are more attractive. The hardness and strength increase clearly in the sample processed at RT. The hardness value has doubled, while the strength increase is by $\sim 50 \%$.

3. The grain boundary misorientation and grain refinement are strongly affected by the processing temperature. The processing temperature also influences the fractions of LAGBs and HAGBs found in the material after RCS processing. Alloy processed at $200{ }^{\circ} \mathrm{C}$ and $300{ }^{\circ} \mathrm{C}$ displays very significant grain growth compared with the specimen processed at RT and $100^{\circ} \mathrm{C}$.
4. The activation energy for the rate controlling process is $\sim 256 \mathrm{~kJ} / \mathrm{mol}$. The microstructure and minor compositional differences are considered to be responsible for the relatively small difference in the activation energy values.

Acknowledgements This work was supported financially by the Department of Science and Technology, Government of India (No. SB/FTP/ETA-104/2012). The authors gratefully acknowledge the help of Prof. V. Subramanya Sarma, IITM, Chennai, for the EBSD measurements.

\section{References}

[1] Y.X. Tong, Y. Wang, Z.M. Qian, D.T. Zhang, L. Li, Y.F. Zheng, Acta Metall. Sin. (Engl Lett.) 31, 1084 (2018)

[2] G. Ji, X.H. Yang, N. Song, S. Min, Rare Met. Mater. Eng. 47, 1347 (2018)

[3] M.R. Morovvati, B.M. Dariani, J. Manuf. Process. 30, 241 (2017)

[4] S.V. Noora, A.R. Eivania, H.R. Jafariana, M. Mirzaeib, Mater. Sci. Eng., A 652, 186 (2016)

[5] N. Thangapandian, S.B. Prabu, K.A. Padmanabhan, Mater. Sci. Eng., A 649, 229 (2016)

[6] Z.S. Wang, Y.J. Guan, G.C. Wang, C.K. Zhong, J. Mater. Process. Technol. 215, 205 (2015)

[7] I. Mazurina, T. Sakai, H. Miura, O. Sitdikov, R. Kaibyshev, Mater. Sci. Eng., A 486, 662 (2008)

[8] A. Goloborodko, O. Sitdikov, R. Kaibyshev, H. Miura, T. Sakai, Mater. Sci. Eng., A 381, 121 (2004)

[9] P. Rodriguez-Calvillo, J.M. Cabrera, Mater. Sci. Eng., A 625, 311 (2015)

[10] L.L. Guo, F. Fujita, J. Magnes. Alloys 3, 95 (2015)

[11] A. Belyakov, T. Sakai, H. Miura, K. Tsuzaki, Philos. Mag. 81, $2629(2001)$

[12] J.P. Li, J. Shen, X.D. Yan, B.P. Mao, Trans. Nonferrous Metall. Soc. China 20, 189 (2010)

[13] S.T. Zhao, C.L. Meng, F.X. Mao, W.P. Hu, G. Gottstein, Mater. Sci. Eng., A 76, 54 (2014)

[14] T. Li, K. Zhang, X.G. Li, Z.W. Du, Y.J. Li, M.L. Ma, G.L. Shi, J. Magnes. Alloys 1, 47 (2013)

[15] V. Sklenicka, J. Dvorak, P. Kral, Z. Stonawska, M. Svoboda, Mater. Sci. Eng., A 410, 408 (2005)

[16] M. Karimi, M.R. Toroghinejad, J. Dutkiewicz, Mater. Charact. 122, 103 (2016)

[17] X. Molodova, G. Gottstein, M. Winning, R.J. Hellmig, Mater. Sci. Eng., A 460, 204 (2007)

[18] N. Kamikawa, N. Tsuji, Mater. Trans. 53, 30 (2012)

[19] M.A. Meyers, A. Mishra, D.J. Benson, J. Mater. 58, 41 (2006)

[20] X.H. An, Q.Y. Lin, G. Sha, M.X. Huang, S.P. Ringer, Y.T. Zhu, X.Z. Liao, Acta Mater. 109, 300 (2016)

[21] S.V. Bobylev, M.Y. Gutkin, I.A. Ovidko, Acta Mater. 52, 3793 (2004)

[22] X.H. An, S.D. Wu, Z.F. Zhang, R.B. Figueiredo, N. Gao, T.G. Langdon, Scr. Mater. 63, 560 (2010) 